\title{
Design and Realization of Big Data Learning Aid System Based on MOOC
}

\author{
Ping HongHai ${ }^{1, *}$ \\ ${ }^{1}$ Jiangxi Vocational and Technical College of Industry
}

\begin{abstract}
At the beginning of 2020, in the face of the sudden new crown epidemic, the Ministry of Education proposed an emergency response policy of "stopping classes without stopping school", and various teaching units have carried out unprecedented online teaching practices. This large-scale online teaching wave has accelerated the development speed and application scope of "Internet + Education". Based on the big data learning support system, with teachers and students as the main body, using big data technology to integrate high-quality teaching resources and reduce teaching Cost, design and implement teaching aid system for teachers and students. Based on massive online learning data, through intelligent analysis of academic data, it will provide learners with learning suggestions, online examinations, teacher-student activities, assist teachers in implementing student evaluations, carry out precise teaching and research, and improve the curriculum resource construction system.
\end{abstract}

\section{INTRODUCTION}

Online open courses are the product of the combination of information technology and education and teaching. It mainly refers to learners' use of online learning platforms and tools for independent learning and communication, so as to obtain the information and resources they need. Since the rise of large-scale online open courses (MOOC) in China in 2012, under the leadership of the Ministry of Education, the education administration departments, universities and course platform operating institutions in all provinces and cities across the country have actively responded to vigorously promote the construction, application, and research of online open courses and management work. The construction of online open curriculum resources in higher vocational colleges across the country has grown rapidly, and a large amount of learner behavior data has been generated in actual applications, and many problems have been exposed: student participation is low, only simple data aggregation can be done, and no data can be provided. Effective learning suggestions, lack of effective evaluation mechanism.

\section{RELATED WORK}

Predecessors have done a lot of research on online education platforms and big data teaching applications. The MOOC platform has more than 6.2 million registered users, more than 20 million learners, and more than 210,000 people have obtained learning certificates. The social response has been good and it has become the first

\footnotetext{
*Corresponding author. Email: 615959823@qq.com;
}

MOOC public service platform in China[1]. Development of a Design Education Platform for an Interdisciplinary Teaching Concept[2]. Research and implementation of network learning platform based on $\mathrm{B} / \mathrm{S}$ architecture[3]. Design and Realization of Excellent Resource Sharing Course System Based on JavaWeb[4]. Design and Implementation of a Web-based Remote Teaching Management System[5]. The Current Situation and Countermeasures of Co-construction and Sharing of "Internet + Education" MOOC Resources in Universities[6]. Open Source Robotic Simulators Platforms for Teaching Deep Reinforcement Learning Algorithms[7]. "Suspension of classes without suspension" during the period of COVID-19 Online teaching case analysis[8]. The Design and Implementation of Network Teaching Platform Basing on .NET[9]. Remote case teaching mode based on computer FPGA platform and data mining[10]. Construction of Double-Precision Wisdom Teaching Framework Based on Blockchain Technology in Cloud Platform[11].

\section{SIGNIFICANCE OF BIG DATA LEARNING AID SYSTEM}

In online learning, a large amount of diverse learner behavior data will be quickly generated. The learning aid system based on big data analysis technology can conduct data mining and learning analysis on learner behavior data from online learning platforms, teaching management platforms, student management and other platforms, and intelligently push open tasks for learning The person explores, researches, and solves it by himself. Students 
can study and research in groups, get different solutions, and use different methods to achieve the same goal. Therefore, it stimulates students to give full play to their imagination and creativity, which is conducive to cultivating students' open thinking and logical thinking. Through active exploration and hands-on practice, students experience firsthand how abstract theories become answers within reach, enhance their sense of selfefficacy, and enjoy the joy and excitement of success.

\section{DESIGN OF BIG DATA LEARNING AID SYSTEM}

The big data learning aid system is a comprehensive system dedicated to the development of an auxiliary teaching system that integrates curriculum resource sharing, interactive communication, homework management, examination management, platform management and other functions.

\subsection{The main design principles of system development:}

(1) Principle of practicality

In the process of system development, the user-friendly interface, beautiful and practical, simple operation should be considered, and the management method of pictures and texts and video playback should be adopted. Each module of the user experience system has a clear step positioning, which reduces the cost of learning operations.

(2) The principle of easy maintenance

The system should provide better background management methods for system administrators and teachers to facilitate the operation of teaching and research staff.

(3) Security principle

The stable operation of the system is inseparable from safety. The core of this course website is content management, which includes the personal privacy of students, teachers, administrators and many other data that need to be protected to prevent illegal intrusion of data and other operations. Encrypted information is added when the user enters the password to ensure the basic security of user information.

(4) Principle of system stability

The design of the system is very complicated. In order to ensure the stability of the system and improve the speed and efficiency of the system, the system adopts advanced distributed system architecture and database technology, and the technology of separation of front and back ends.

(5) Correspondence: The learning aid system should have strong pertinence for online learning behavior analysis, and be able to effectively set tasks according to the needs of learners. In the analysis process, the learning process and analysis should be considered. Effective response to tasks.

Big Date Learning Aid System model is shown in the figure 1 .

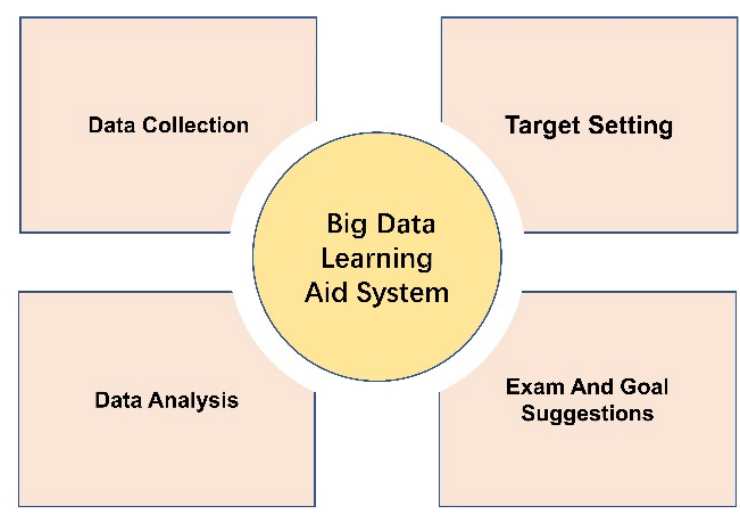

Figure 1 Big Date Learning Aid System model

\subsection{System function requirement analysis:}

The main functional modules of the big data learning aid system: teaching resource management, forum management, homework management, examination management, platform management.

(1) Demand analysis of teaching resource management module.

In the teaching resource management module, teachers can add, modify, delete and query learning materials to maximize the effect of course resource sharing; students can learn learning materials uploaded by teachers on the Internet. View resources Students, teachers and website visitors can view the course resources provided by the system through this system, and obtain the required resources through the course resource sharing module. After the user enters the system homepage, click the search box to enter the search content to perform a fuzzy search, so as to obtain the corresponding related information. Resource download resource upload.

(2) Demand analysis of forum management module

This module is designed in the form of a post bar, and the purpose is to provide teachers and students with a convenient communication platform to share their experiences and make progress together. Teachers and students can use this module to post, browse, query, and reply. In addition, teachers and administrators also have permission to review posts. System users can use this module to share their own learning experiences, problems encountered in learning, etc. The main purpose is to provide students with a convenient communication platform and solutions when they encounter problems in the learning process.

(3) Demand analysis of job management module.

The biggest feature of this module is to get rid of the traditional classroom offline submission of homework and manual correction methods, to achieve modern teaching. Through this system module, teachers can upload homework and correct homework, and students can browse the dynamics of homework online, upload and submit homework.

(4) Requirement analysis of examination management module.

In the test management module, before the student takes the test, the system administrator and teacher can add, delete, modify, query, set test parameters, automatic 
test paper composition, test paper management and other operations in the question bank; when the test starts, students can $\log$ in to the system to participate online Examination: After the examination, the system combines automatic scoring of objective questions and manual scoring of subjective questions, and finally the total score is obtained. Students can view the ranking of the exam and analyze the reference answers.

Main functional structure diagram of Big Date Learning Aid System is shown in the Figure 2.

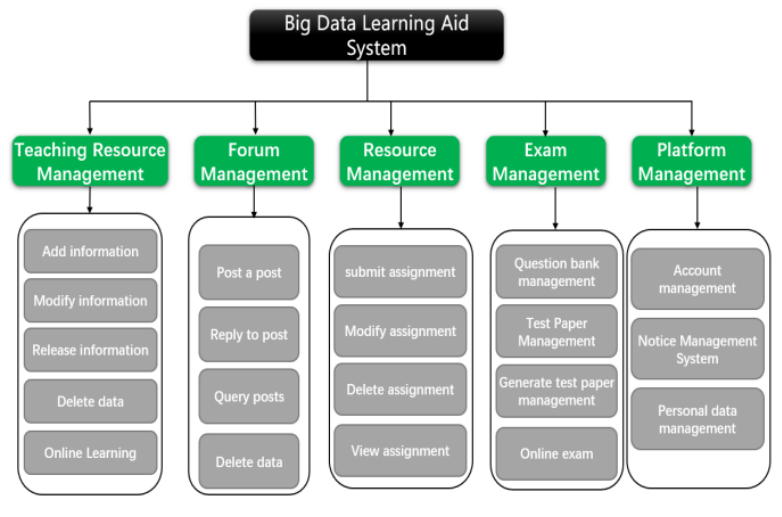

Figure 2 Main functional structure diagram

\subsection{Big data learning aid system Functional Analysis:}

A learning aid system based on big data analysis should have the following basic functions:

1. User login: realize user classification for login. Each type of user uses different system permissions, and provides corresponding levels of services and operations according to their identities.

2. User management: realize the management and maintenance of user information and authority.

3. Index management: realize the management and setting of all measurement indexes.

4. Information collection: realize the collection function of all kinds of related information appearing on the online platform. Including the collection of learning data and specific text content in interactive communication.

5. Learning data analysis: realize the corresponding analysis of the collected learning data, and get the corresponding next action recommendations.

6. Hot spot analysis: Realize the analysis of the collected specific text, including Chinese word segmentation and text analysis, and get the hot learning issues that learners pay attention to, and help teachers form next teaching suggestions.

7. Result display: realize the function of displaying and recording the results of information analysis.

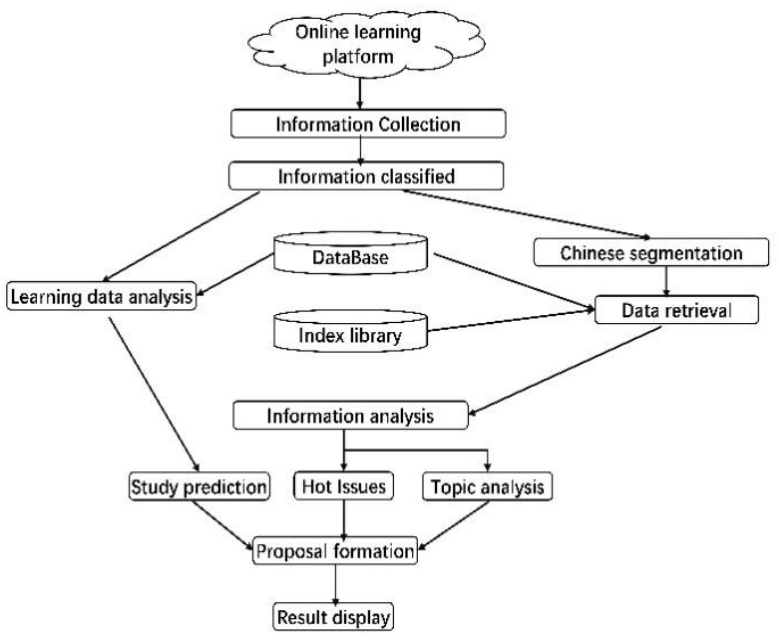

Figure 3 work flow chart of Big Date Learning Aid System

\section{CONCLUSION}

Through big data statistical analysis, students' performance can be obtained and key obstacles can be found. After a period of accumulation, the system will issue a detailed summary report for the student's learning status to achieve expert guidance that varies from person to person.

Integrate the learning aid system based on big data analysis technology into the entire learning process of online open courses, accurately analyze the learning behavior data of each learner, provide each learner with effective suggestions and references based on big data, and simulate the teacher's completion of learning Guidance and supervision; assist teachers to implement student evaluation, carry out precision teaching and research, and improve the curriculum resource construction system.

Online learning with the support of big data not only provides personalized support for each individual, but also provides support for groups with an ecological nature. We must continue to uphold the comprehensive development of the education concept of "ethics, intelligence, physical education, and labor". Do a good job in the "build, use, and learn" of online open courses, build online teaching resources that meet the characteristics of vocational education "skills" training, actively explore the role of big data technology in online learning, and continue to conduct online education under the background of "Internet + education". Exploration and Practice of Education and Teaching Reform.

\section{ACKNOWLEDGMENTS}

Thank the work unit for giving us a superior platform to write papers and obtain experimental data, thank the partners for their strong support, and thank the family for their selfless dedication. Without your support, we would not be successful. 


\section{REFERENCES}

1. DaLiang, Z., Speech at the Chinese University Online Open Course Forum. Chinese University Online Open Course Forum, 2017: p. 11-13.

2. Emil Heyden, J.K., Erik Greve, Dieter Krause, Development of a Design Education Platform for an Interdisciplinary Teaching Concept. Procedia, 2020: p. 553-558.

3. YaZhu, S., Research and implementation of network learning platform based on B/S architecture. Master's Degree Thesis, 2018.

4. Yun, L., Design and Realization of Excellent Resource Sharing Course System Based on JavaWeb. Master's Degree Thesis, 2018.

5. Xiong ZiDong, Z.Z., Design and Implementation of a Web-based Remote Teaching Management System. Application R\&D, 2019: p. 269-271.

6. Wang Guirong, T.Y., Ma Lijuan, The Current Situation and Countermeasures of Co-construction and Sharing of "Internet + Education" MOOC Resources in Universities. Teaching of Forestry Region, 2019: p. 25-28.
7. Armando Plasencia , Y.S., Ileana Suárez, Zoila Ruiz Open Source Robotic Simulators Platforms for Teaching Deep Reinforcement Learning Algorithms. Procedia Computer Science, 2019: p. 162-170.

8. Wang Hongxin, H.S., Xu Jin, "Suspension of classes without suspension" during the period of COVID-19

Online teaching case analysis. Modern Bussness Trade Industry, 2020: p. 163-165.

9. Yanna, R., The Design and Implementation of Network Teaching Platform Basing on .NET. Physics Procedia, 2012. 25: p. $892-898$ DOI: https://doi.org/10.1016/j.phpro.2012.03.174.

10. Rong, L., Remote case teaching mode based on computer FPGA platform and data mining. Microprocessors and Microsystems, 2021. 83 DOI: https://doi.org/10.1016/j.micpro.2021.103986.

11. Liu, S., et al., Construction of Double-Precision Wisdom Teaching Framework Based on Blockchain Technology in Cloud Platform. IEEE Access, 2021: p. 1-1 DOI: https://doi.org/10.1109/access.2021.3051468. 